\title{
The Impact of the General Data Protection Regulation on the Design and Measurement of Marketing Activities: Introducing Permission Marketing and Tracking for Improved Marketing \& CRM Compliance with Legal Requirements
}

\author{
Victoria-Anne Schweigert \\ Karlsruhe Institute of Technology (KIT) \\ Andreas Geyer-Schulz \\ Karlsruhe Institute of Technology (KIT)
}

It is important to design marketing and CRM campaigns in accordance with the customer's requirements. A good way to collect information for the creation of a purposeful campaign is the usage of feedback and knowledge of previous campaigns. But the introduction of the GDPR 2016/679 in May 2018 makes the measurement of consumer behavior in a law-conforming way more challenging. This contribution discusses user behavior measurement methods which are compatible with the GDPR. It illustrates the impact of the new regulation on user communication in the context of email campaigns and of social media marketing in Facebook. We show that the implementation of Godin's permission marketing approach is a blueprint for GDPR compatible marketing communication activities (Godin, 1999).

Keywords: General Data Protection Regulation, Advertising Tracking System, Permission Marketing

\section{MOTIVATION}

To improve the reach and prominence of a scientific journal advertising is important. But how can we know which scientific marketing activities are successful and which are not effective? Are other factors important in the scientific environment than in typical commercial markets, e.g. another time slot to reach the potential customer? Do customers react in their professional part different than in the private environment? Can we find user reactions specific to social media platforms? To answer these questions, marketers need to measure, manage and fine-tune their campaigns. But the introduction of the General Data Protection Regulation 2016/679 (GDPR) in May 2018 makes the measurement of consumer behaviour in a law-conforming way more challenging. In this contribution, we introduce our inhousedeveloped tracking system, called KITAnalytics, that complies with the GDPR. Furthermore, the contribution illustrates the impact of the new regulation on user communication in the context of email campaigns and of social media marketing in Facebook and discusses important requirements for the measurement of user behaviour. We show that Godin's permission marketing approach - when properly implemented - is a blueprint for GDPR compatible marketing communication activities (Godin,1999). 
We consider the possibilities to design advertising more valuable and anticipated by the customer by considering the new regulations.

\section{INTRODUCTION TO THE RESEARCH ISSUE}

Communication is the most important factor to build a long-term relationship and it is the basis of customer-focused marketing activities (Duncan \& Moriarty, 1998). It is very important to know which marketing communication activities are appealing and reach the customer. To acquire this important information, it is necessary to measure all marketing communication activities which implement a marketing or Customer Relationship Management (CRM) strategy. Advertising is only successful if it is purposeful. Godin (1999) introduces permission marketing as a marketing communication strategy which is based on messages which are anticipated by the user, personalized and relevant. Marinova, Murphy \& Massey (2002) support this approach as well. To make messages more anticipated, personalized and relevant for the user, learning from user behaviour plays a fundamental role in permission marketing. Technically, this implies that tracking of the dialogue between the marketers and the consumer is implemented and conforms to the GDPR. Also, Stone and Jacobs (2001) show how important tracking is. According to Stone and Jacobs, "Direct Marketing is the interactive use of advertising media, to stimulate an (immediate) behaviour modification in such a way that this behaviour can be tracked, recorded, analysed, and stored on a database for further retrieval and use" (Stone \& Jacobs, 2001, p.5). So, it is necessary to use a tracking system to measure the success of the different marketing communication activities to maintain and fine-tune the present campaign, gain feedback and develop future successful and appealing marketing campaigns. Marketers need a method to evaluate the success of the implemented campaigns. But since the mandatory application of the General Data Protection Regulation in May 2018 (European Parliament and of the Council, 2016) it is more problematic to measure customer behaviour for marketing goals. The same problem affects market research. Consequently, many commercial products to measure the success of marketing strategies are no longer compatible with the GDPR (e.g. Facebook Insights without adaption) (Stehmeier, 2018).

In this paper, we focus on measuring methods which are conform to the legal requirements in Europe. Next, we introduce the GDPR and show our GDPR conforming tracking system KITAnalytics to measure marketing communication activities. But we are not only showing the negative impact of the GDPR, the rules also bring a positive impact and make advertising more successful and honest from the view of customers. In the best case, marketing messages are more anticipated and more relevant for the customer. As scientific environment for the development we used the scientific journal Archives of Data Science. This journal is perfectly suitable as scientific environment to explore successful scientific marketing and CRM strategies on the condition that these methods comply with the GDPR, because we aim to improve the reach and prominence of the scientific journal by measuring and tracking marketing campaigns across different channels, like social media platforms, and to improve the content and design of campaigns.

\section{INTRODUCTION TO THE SCIENTIFIC TEST ENVIRONMENT}

The journal Archives of Data Science, Series A (www.archivesofdatascience.org, AoDS) publishes papers of short to medium length in the emerging field of data science. The journal covers regular research articles from the field of Data Science and special issues. Every fully reviewed and accepted paper will be published with a unique DOI in an online-first version that is freely available and already quotable. We integrated and use the tracking system KITAnalytics to develop appealing marketing and CRM campaigns for this journal. By extracting the tracked data, we are able to measure the success of every marketing activity and we create guidelines for successful marketing in this area based on explorative analysis. 


\section{THE GENERAL DATA PROTECTION REGULATION (GDPR)}

The Data Protection Law plays a significant role for several years. Especially a small or mediumsized company or a scientific organization needs time to understand it and adapt its marketing activities or marketing research. In May 2016 (25.05.16) the GDPR was introduced and since May 2018 (25.05.18) the application is mandatory in the European Union (EU). The GDPR is a regulation in EU law for data protection and privacy. It includes all individuals within the EU and the European Economic Area (EEA) and standardises the rules for processing personal data by private companies and public authorities across the EU. In addition, it regulates the export of personal data outside the EU and EEA areas (European Parliament and of the Council, 2016). The new regulation has an impact on all types of marketing activities. In part, the General Data Protection Regulation simplifies some marketing activities in some European Countries, e.g. email marketing for existing clients in Germany. It is important for marketers to consider these requirements to offer a legally compliant implementation of marketing activities. This is not only important, because there is the possibility of public law penalties, but also because the general image of an advertising company suffers, if the advertising method is in a regulatory grey area. The GDPR introduces new regulations, which need to be considered, but it also offers the chance to rethink some marketing activities and to build a more trustful relationship between the customer and the provider/marketer.

In fact, there are three important parts that marketers need to care about, namely regulations covering data permission, data access and data focus (GDPR Associates, 2018).

\section{Data Permission}

This part is about email marketing, especially the requirements of "opt-ins". That means, that marketers are not allowed to assume that users would like to be contacted by them. Users need to give a consent in a "freely given, specific, informed, and unambiguous" way, which is reinforced by a "clear, affirmative action" according to the Article 29 Data Protection Working Party of Directive 95/46/EC (European Parliament and of the Council, 2011; Hert \& Papakonstantinou, 2016). That means in practice, that marketers need a permission (a confirmation) to contact the customers. This idea was already standard in the data protection law of many EU countries, like Germany.

\section{Data Access}

This part of the regulation relates to the "right to be forgotten". According to the GDPR Associates this "has become one of the most talked about rulings in EU Justice Court history" (GDPR Associates, 2018). It means, that the customer is able to request that a company or an organization has to remove all collected and stored data about this specific user (Ausloos, 2012). The request for deletion has to be easy for the user.

\section{Data Focus}

This means that a marketer is only allowed to collect, process and store the data he or she really needs. Every collected user activity and the metadata needs to be necessary for the advertising target. No exception for exploratory scientific research is granted.

\section{THE GDPR \& PERMISSION MARKETING - THE CHANCE FOR BETTER MARKETING}

These three important areas of the GDPR give an impetus to adapt a permission marketing strategy to comply with the GDPR. The main reason is that permission marketing has an excellent fit with the legal requirements of the GDPR: 


\section{Data Permission}

Opt-in respects the principle of customer sovereignty and attracts only customers interested in the campaign. This self-selection increases the success of subsequent marketing activities and avoids the harassment of consumers (Kumar at al., 2014).

\section{Data Access}

Permission marketing claims that opt-outs are another opportunity to show respect to the customer and that this helps in relation-building. Obviously, opt-outs are an elegant implementation of the right-tobe-forgotten (data access), provided that the opt-out also destroys all links between the consumer and his/her behavioral data. This also implies a restructuring of the internal data model towards pseudonyms. Permission marketing shows, that advertising is only successful, if the user really wants it. To inspire trust between marketer and client it is useful to communicate the possibility to opt-out, e.g. to show already during the subscription, that there is always an easy way to unsubscribe. People expect honesty in marketing. This part of the regulation provides an opportunity to improve the own marketing and CRM campaigns, because it gives the user a feeling of security and honesty.

\section{Data Focus}

In permission marketing the customer determines, how deep the relationship is and he/she gives the permission for advertising on different levels (Godin, 1999). The user controls, which and how much data the provider gets. Openness and controllability of the stored and collected data is important.

The requirements resulting from the data focus of the GDPR have a strong impact on the design of the tracking system. The collected data needs to be necessary for the objectives of the activities. For example, do we really need to know the date of birth or the name of a user of the Archives of Data Science to improve marketing and CRM activities? Of course, it would be nice to personalize the website or an email with the name of the user or use different contact channels depending on the age of the recipient. But this is not a part of the tracking service. If marketers want to add such specific parameters to their research, they need to use another way to collect the data (for example with the help of a personal account created with the consent of the user). Our inhouse-developed tracking system KITAnalytics delivers the possibility to maintain and to fine-tune actual campaigns, gain feedback of previously implemented marketing activities and discover information about the different marketing channels. For this reason, we do not need to store personal data, it is enough to use the data in a pseudonymized way.

In contrast, consider the user groups authors or reviewers: We need to collect and store their names, because it would not be possible to manage a scientific journal without this data. But the important difference is, that this data is not stored for marketing purposes, it is stored for the working process. And second, this data is not tracked and not distributed to third parties. The user gives us the data voluntarily.

\section{THE GDPR \& FACEBOOK - THE IMPACT OF SOCIAL MEDIA MARKETING}

A Facebook fanpage belongs to the standard channels for marketing activities of many organizations or companies. But the introduction of the GDPR changes the legal framework for using this marketing tool in Europe. This leads to the question: "Is the operation of a Facebook fanpage still legally contested?" The European Court of Justice (ECJ) judgment C-210/16 (European Court of Justice, 2018) according to the Facebook site operator Wirtschaftsakademie Schleswig-Holstein of June 5, 2018 implied a co-responsibility for the data protection of Facebook site operators (beck-aktuell, 2018; Unabhängiges Landeszentrum für Datenschutz Schleswig-Holstein, 2018). The judgement led to an insecurity with regard to the liability in case of a data protection breach on a fanpage. The problem is, that Facebook Insights (the Facebook Tracking Tool) collects, processes and stores personalized data and the Facebook fanpage operator receives a part of this information automatically. The operator is not able to switch the service off or ask the users of the fanpage for consent before the user enters the webpage. Also, the responsible data protection authorities in Germany rate the current functioning of Facebook pages as not compliant with the GDPR (Kasanmascheff, 2018). Subsequently, many Facebook site operators closed 
the fanpages until Facebook will change the disputed practices. Facebook responded to these closings and announced an update on June 15th, 2018. In accordance with Facebook's announcement the coresponsibility for the data protection should be removed. But in the Page Insights Controller Addendum (announced in late 2018) Facebook claimed co-responsibility of Facebook and page operators and regulated the responsibilities of page operators with regard to Facebook (Facebook Ireland Limited, 2018). Currently, a page operator is not able to switch off tracking by Facebook Insights.

\section{THE GDPR \& TRACKING - THE IMPACT OF THE MEASUREMENT OF MARKETING ACTIVITIES}

There are many limitations by the GDPR for the implementation and use of a tracking and measurement system. In this contribution, we explain, why our system KITAnalytics resigns from the storing of IP addresses and using standard cookies, fingerprinting or personal profiles. Next, we show, how we solved this problem by showing alternatives to store the needed data. For marketers, it would be nice to have real user tracking to recognize how often users visit a site and for which reasons.

\section{IP Addresses}

One way to archive session information about the users is the storage of IP addresses. The GDPR prohibits to save full IP addresses to track users, because this data is personalized. Only the storage of the IP addresses in a shortened way is compliant with the GDPR. The storage of shortened IP addresses provides no added value and is useless, because shortened versions of the IP addresses are too similar. A scientific journal often has clients from universities. Normally, a university or a company uses only a few IP addresses (around four different addresses) in their networks. In addition, user IP addresses are locally and dynamically assigned and IP addresses are translated several times when passing firewalls.

A consequence of this is that measuring IP addresses (short or full) is at least for the scientific community of limited or no value at all. In a shortened way the IP addresses are identical and provide no added value.

\section{Cookies}

Another idea is to use cookies to track the customer journey. The usage of tracking cookies is not useful for the measurement service, because a lot of users forbid or delete them often. Normally, in a lot of browsers cookies are already forbidden in the factory settings or the factory settings effects that they are automatically deleted by every closing of the browser. For this reason, they are completely useless. In addition, some browser applications (e.g. Adobe Director) set their own state-variable containers (aka cookies) and override the browser set access controls. They thus provide trap-doors to user systems and are, while useful, not compliant to the GDPR. Our measurement system works with session cookies. These cookies are often accepted by the user, because they improve the user experience on many websites. But the session cookies store no user history and are only helpful for a short time period. Also, these cookies are often automatically deleted by every closing of the browser. But they allow session identification in our tracking environment.

\section{Fingerprinting}

Fingerprinting relies on the possibility of reading the configuration of the users and that because of the large state space of possible configurations the probability that two users have the same state of configuration is almost zero $\left(\approx 10^{-12}\right)$. It seems to be a good way to track users or more concrete devices, but the GDPR is very concrete in its regulations of fingerprinting. Device fingerprinting is only permitted with the consent of the user, a necessity to deliver an explicit wished service and only used for the data transfer. It is not compliant with the GDPR to use fingerprinting for behavioural targeting or research purposes. 


\section{Login}

Another possibility to collect information about the user is the requirement of a login before the user enters the website. Every user would be pressured to create a personal account. This is a bad idea, because it repels potential new customer. In fact, we are collecting data to create appealing marketing activities to increase the number of customers, so, it is obstructive to build such barriers. A new user will not create an account just for a trivial visit of the AoDS website. Especially, readers would not enter the website. A login obligation is only possible for submitting a paper.

\section{TRACKING SYSTEM - INTRODUCING THE GDPR COMPATIBLE SYSTEM KITAnalytics}

In view of the discussed requirements, we designed our inhouse-developed tracking system KITAnalytics, which is compatible with the GDPR (especially with the requirement of data focus). Because of the requirements of the GDPR it is used in combination with the well-known tracking service Matomo (previously Piwik). The architecture of KITAnalytics is based on the log manager system of Gray and Reuter (1993). The system allows the tracking of user behaviour on selected observation spots of the website (activity dispatch) in a systematic and enriched way without the storage of IP addresses or Fingerprinting (Like mention in section "The GDPR \& Tracking - The Impact of the Measurement of Marketing Activities"). Further valuable impact on useful user activities came from different studies, papers and practical experiences (Hassler, 2012; Kumar et al., 2012; Mullarkey, 2004; Phippen et al., 2004).

The tracking system currently distinguishes between two important user activities, namely DownloadPaper and ViewPage (both in combination with a specific tracking code). The action DownloadPaper shows that a user clicked on the Get-Article- or Get-Volume-button on the website of the journal AoDS. The system stores the following metadata attributes for this activity: Action, title of contribution, name of authors, DOI, date of activity, 30-minutes cookie, and tracking code. The date of the activity consists of the German time (local time of the AoDS) and the client time. A 30-minutes cookie provides a heuristic to recognize sessions. The second action ViewPage shows a view of one page of the journal website. It could be the homepage or one of the subpages. Every opening of one page of the web presence will be counted as a view. The metadata for the activity ViewPage consists of the following attributes: Action, date of activity, page, referrer, 30-min cookie, and tracking code. The referrer shows the previously viewed website. This allows us to track the origin of the user and in which sequence he or she visited the subpages of the webservice of AoDS.

The measurement and tracking system KITAnalytics is embedded in the service infrastructure of the Archives of Data Science environment. All the tracked data is stored in a database. This database builds the base for further statistical evaluations. Depending on the size of the data, users are able to choose between a python script or a graphical interface to extract data. At the core of the system is the tracking code. A tracking code is unique for each marketing activity and the metadata of the tracking code describes the marketing activity. Tracking codes link event-log records with marketing activities and allow the analysis of dynamic reactions of user groups to marketing stimuli. We are able to assign unique tracking codes for different marketing actions, like a post on a social network, an email or a banner. Based on the unique code we collect information about the impact of our marketing activities on different channels and on the reach and prominence of the journal. To track analogue (offline) marketing activities, as well, the system uses QR-codes with unique tracking codes. This implements the possibility to track analogue marketing activities, like flyers, posters or advertising in a printed conference volume. Because of the GDPR limitations and to design the system GDPR compatible, we combined the tracking and measurement system KITAnalytics with the measurement system Matamo (Innocraft, 2018). It is possible to identify sessions during a visit with KITAnalytics, but it is not possible to recognize, if the user has been on our webpage before. We started to use Matomo as a second measurement system, to track repeat visits. Another advantage is, that we can compare the data of both systems to check for errors in measurement. The use of Matamo is lawful, because it is an open source software, the data is stored on our own server without access of third parties and we see only pseudonymized user profiles. The system 
enables us to store, if the user is a new or a recurring visitor and offers a pseudonymized user profile to show how often and how long the user was on the website. The following metadata attributes are stored in a pseudonymized user profile: The start date and length of stay and the location (country) of the user and device information, like the type of the browser, including plugins, the language, type of operating system and screen size. This was used for usability testing to improve the research environment to ensure that the marketing activities will not fail, because the journal website cannot be entered with specific devices (Schweigert \& Geyer-Schulz, 2018). Of course, the different actions ViewPage and DownloadPaper will be stored as well. The combination of both systems allows us to identify sessions and to maintain the measured data. Furthermore, based on the measured data we are able to derive guidelines for further marketing activities by conducting an explorative analysis.

\section{CONCLUSION}

Targeted communication with the customer is very important to build a long-term relationship. For this reason, it is important to design marketing and CRM campaigns in accordance with customer requirements. A good way to collect information for the creation of such a purposeful campaign is the usage of feedback (Duncan \& Moriarty, 1998; Patterson, 2016; Schramm, 1973; Sharma \& Patterson, 1999) and the knowledge of previous campaigns. Tracking helps marketers to collect data of communication activities for the creation of future purposeful marketing and CRM activities. This contribution demonstrates the complexity of the tracking including the collection, storage and processing of data since the introduction of the GDPR. This implies additional complexity by using software of different providers. In some cases, it is helpful to use a combination of different products (like our system) to fulfil the legal requirements, in other cases, it is problematic to use services, especially from outside the EU, which are still not adjusted by the GDPR. For example, this restrains social media marketing campaigns, like the operation of a Facebook fanpage for a scientific journal. This contribution introduces important changes in the GDPR, especially the regulations on data permission, data access, and data focus, and shows which points are important for the development of a marketing campaign or in market research. In this contribution, we illustrate both negative impacts of the GDPR as well as to make advertising more valuable and anticipated for the customer. Proper implementation of the permission marketing approach fulfils the requirements of the GDPR. Second, the contribution demonstrates our tracking system, which is in accordance with the GDPR. 


\section{REFERENCES}

Archives of Data Science. (2018). Website of the Journal Archives of Data Science. Series A ISSN: 23639881; Series B ISSN: 2510-0564 [website]. Retrieved from http://www.archivesofdatascience.org/journals/aods

Ausloos, J. (2012). The 'Right to be Forgotten':Worth remembering?. Computer Law \& Security Review, $28(2), 143-152$.

beck-aktuell. (2018, June 5). EuGH: Betreiber einer Facebook-Fanpage haftet gemeinsam mit Facebook für Verarbeitung personenbezogener Daten auf Fanpage [website]. Retrieved from https://rsw.beck.de/aktuell/meldung/eugh-betreiber-fanpage-haftet-gemeinsam-mit-facebookfuer-datenverarbeitung

Duncan, T., \& Moriarty, S.E. (1998). A communication-based marketing model for managing relationships. Journal of Marketing, 62(2), 1-13.

European Court of Justice. (2018, June 5). Judgment c-210/16 [website/PDF]. Retrieved from http://curia.europa.eu/juris/document/document.jsf;jsessionid=9ea7d0f130dca65366637da945718 436f7aa3ce64fa0.e34KaxiLc3eQc40LaxqMbN4Pb3uSe0?text=\&docid=202543\&pageIndex $=0 \& d$ oclang $=\mathrm{EN} \&$ mode $=1$ st $\&$ dir $=\&$ occ $=$ first $\&$ part $=1 \&$ cid $=4593981$

European Parliament and of the Council. (2011, July 13). The Working Party On The Protection Of Individuals With Regard To The Processing Of Personal Data set up by Directive 95/46/EC of the European Parliament and of the Council of 24 October 1995 - Opinion 15/2011 on the definition of consent - Article 29 Data Protection Working Party of Directive 95/46/EC: 01197/11/EN WP187 [PDF]. Retrieved from https://ec.europa.eu/justice/article-29/documentation/opinionrecommendation/files/2011/wp187_en.pdf

European Parliament and of the Council. (2016). Regulation (EU) 2016/679 of the European Parliament and of the Council of 27 April 2016 on the protection of natural persons with regard to the processing of personal data and on the free movement of such data, and repealing Directive 95/46/EC (General Data Protection Regulation). Official Journal of the European Union, L119,188.

Facebook Ireland Limited. (2018, September 12). Page Insights Controller Addendum [website]. Retrieved from https://www.facebook.com/legal/terms/page_controller_addendum

GDPR Associates. (2018, April 27). The GDPR: How Will New EU Data Privacy Regulations Affect Marketing? [website]. Retrieved from https://www.gdpr.associates/gdpr-will-affect-marketing/

Godin, S. (1999). Permission Marketing: Turning Strangers Into Friends And Friends Into Customers. New York: Simon \& Schuster.

Gray, J., \& Reuter, A. (1993). Log Manager. In Gray, J., \& Reuter, A., Transaction Processing: Concepts and Techniques (pp 493 - 525). San Mateo: Morgan Kaufmann Publishers.

Hassler, M. (2012). Web Analytics: Metriken auswerten, Besucherverhalten verstehen, Website optimieren (3th ed.). Heidelberg:Verlagsgruppe Hüthig-Jehle-Rehm.

Hert, P., \& Papakonstantinou, V. (2016). The new General Data Protection Regulation: Still a sound system for the protection of individuals? Computer Law \& Security Review, 32(2), 179-194.

Innocraft (2018) Information about Matomo. URL http://Matomo.org

Kasanmascheff, M. (2018, September 18). DSGVO-Mängel bei Facebook-Seiten: Neue Funktionen sollen Probleme beheben: Beschluss der Datenschutzaufsichtsbehörden (netzwelt Hamburg 12.09.18)[Website]. Hamburg. Retrieved from https://www.netzwelt.de/news/167425-dsgvomaengel-facebook-seiten-neue-funktionen-probleme-beheben.html

Kumar L., Singh, H., \& Kaur, R. (2012, August). Web analytics and metrics: A survey. In ICACCI '12. Proceedings of the International Conference on Advances in Computing, Communications and Informatics (pp. 966-971). Chennai, India, NY: ACM.

Kumar, V., Zhang, X.L., \& Luo, A. (2014). Modeling Customer Opt-In and Opt-Out in a PermissionBased Marketing Context. American Marketing Association, 51(4), 403-419.

70 Journal of Marketing Development and Competitiveness Vol. 13(4) 2019 
Marinova, A., Murphy, J., \& Massey B.L. (2002). Permission e-mail marketing: as a means of targeted promotion. The Cornell Hotel and Restaurant Administration Quarterly, 43(1), 61-69.

Mullarkey, G.W., (2004). Internet measurement data: Practical and technical issues. Marketing Intelligence \& Planning, 22(1), $42-58$.

Patterson, P. (2016). Retrospective: tracking the impact of communications effectiveness on client satisfaction, trust and loyalty in professional services. Journal of Services Marketing, 30(5), 485489.

Phippen, A., Sheppard, L., \& Furnell, S. (2004). A practical evaluation of web analytics. Internet Research, 14(4), $284-293$.

Schramm, W.L. (1973). Men, messages, and media: A look at human communication. New York: Harper Row.

Schweigert, V-A., \& Geyer-Schulz, A. (2018). Improving the First Impression of an Online Scientific Publishing Service: A Usability Test. Archives of Data Science, Series A, 4(1), 1-21 (Online First Version).

Sharma, N., \& Patterson, P.G. (1999). The impact of communication effectiveness and service quality on relationship commitment in consumer, professional services. Journal of Services Marketing, 13(2), 151-170.

Stehmeier, M. (2018, October 22). Anleitung: Informationspflichten auf Facebook Fanpage von Herting Oberbeck Datenschutzkanzelei [Website]. Retrieved from https://www.datenschutzkanzlei.de/anleitung-informationspflichten-auf-facebook-fanpage/

Stone, B., \& Jacobs, R. (2001). Successful Direct Marketing Methods (7th ed.). New York: McGraw-Hill.

Unabhängiges Landeszentrum für Datenschutz Schleswig-Holstein. (2018, April 24). Urteilsverkündung des EUGH in Sachen Facebook-Fanpages [press releases]. Retrieved from https://www.datenschutzzentrum.de/artikel/1223-Urteilsverkuendung-des-EuGH-in-SachenFacebook-Fanpages.html 